\title{
Effects of the Changes of Load and Flue Gas Temperature on the Emission of Particulate Matter from the Coal-fired Unit
}

\author{
Yujia Wu, Zhenyao Xu, Siqi Liu, Minghui Tang, Shengyong Lu*
}

State Key Laboratory of Clean Energy Utilization, Institute for Thermal Power Engineering, Zhejiang University, Hangzhou 310027, China

\begin{abstract}
Due to the rapid development of new energy power generation, most coal-fired power plants cannot always operate at full capacity. The changes in flue gas temperature at the inlet of lowlow temperature electrostatic precipitator and unit load are the important factors affecting the emission of condensable and filterable particulate matter (CPM and FPM). CPM and FPM were sampled from a typical ultra-low emission coal-fired power unit with different operating loads $(650,850$, and $1000 \mathrm{MW})$ and flue gas temperature $\left(90\right.$ and $\left.100^{\circ} \mathrm{C}\right)$. The emission concentration of FPM, organic and inorganic components of CPM were obtained. The representative organic matter n-alkanes and phthalates in CPM (C-N and C-P) were quantified. The concentrations of CPM emitted from the coal-fired unit ranged from 6.66-8.93 $\mathrm{mg} \mathrm{Nm}^{-3}$, which was 2.4-6.2 times higher than FPM. The emission concentration of CPM was the lowest from the unit under high load and low flue gas temperature. The decrease of flue gas temperature increased of $\mathrm{SO}_{4}{ }^{2-}$ emission concentration, which was the soluble ion with the highest concentration in CPM. The effect of unit load and flue gas temperature changes on monocomponent $\mathrm{C}-\mathrm{N}$ and $\mathrm{C}-\mathrm{P}$ was limited; however, the effect on its total emission concentration was consistent with that on CPM. The concentrations of $n$-alkanes and phthalates in CPM accounted for more than $20 \%$ at all four stages.
\end{abstract}

\section{OPEN ACCESS}

Keywords: Coal-fired power unit, Condensable particulate matter, Filterable particulate matter, Emission characteristics

Received: October 5, 2021

Revised: December 20, 2021

Accepted: February 23, 2022

${ }^{*}$ Corresponding Author: lushy@zju.edu.cn

Publisher:

Taiwan Association for Aerosol Research

ISSN: $1680-8584$ print

ISSN: 2071-1409 online

cc) Copyright: The Author(s). This is an open access article distributed under the terms of the Creative Commons Attribution License (CC BY 4.0), which permits unrestricted use, distribution, and reproduction in any medium, provided the original author and source are cited.

\section{INTRODUCTION}

According to statistics (BP, 2020), coal is primarily used as fuel in China, which still accounted for nearly $60 \%$ of China's primary energy consumption in recent years. China's total thermal power generation accounts for more than $70 \%$ of the total power generation, occupying an absolute dominant position. What is not allowed to ignore however is multiple pollutants such as particulate matter (PM), sulfur dioxide $\left(\mathrm{SO}_{2}\right)$, and nitrogen oxides $\left(\mathrm{NO}_{\mathrm{x}}\right)$, and organic pollutants are emitted from coal combustion, which causes unfavorable effects on the environment and human health (Wang et al., 2016; Tong et al., 2018; Lu et al., 2020; Zhang et al., 2020; Zhou et al., 2020; Sun et al., 2021; Wu et al., 2021a). Ultralow-emission retrofits for coal-fired power plants (CFPPs) have been implemented in China for years (Ruan et al., 2019). At present, the emission concentrations of conventional pollutants ( $\mathrm{PM}, \mathrm{SO}_{2}$, and $\mathrm{NO}_{\mathrm{x}}$ ) from CFPPs have met the standard of less than 10, 35, $50 \mathrm{mg} \mathrm{Nm}^{-3}$, respectively (Li et al., 2017b; Yang et al., 2021). Many effective dust removal, desulfurization, and denitrification technologies have been formed and applied in the field of coal combustion (Xu et al., 2000; Zhang et al., 2006; You and Xu, 2010; Zheng et al., 2018b).

Primary PM discharged from stationary sources of coal combustion can be divided into filterable particulate matter (FPM) and condensable particulate matter (CPM) according to their physical and chemical properties (Feng et al., 2021). FPM is particles that could be physically captured on 
a filter during sampling. CPM is particles that existed in the vapor phase during sampling and condensed to sub-micrometer particles after cooling (Li et al., 2017b; Qi et al., 2017). However, CPM is gaseous in the coal-fired flue gas before being emitted into the atmospheric environment, which allows it to penetrate the filter membrane and existing air pollution control devices (APCDs); thus, the CPM concentration is not included in the total PM (TPM) measurement, the final concentration of TPM will be critically underestimated (Lu et al., 2019; Wu et al., 2020). Because it is not easy to monitor and control, CPM has become a current hot issue and received widespread attention (Tsukada et al., 2008; Cano et al., 2017; Feng et al., 2018; Wang et al., 2019). There are recent studies (Yang et al., 2014; Li et al., 2017b; Morino et al., 2018; Yang et al., 2018; Zheng et al., 2018a; Li et al., 2019; Song et al., 2020) of CPM emission from stationary sources proved that CPM emission concentrations exceed FPM from coal-fired units. Besides, the small particle size (belonging to $\mathrm{PM}_{2.5}$, fine particles with an aerodynamic diameter of $2.5 \mathrm{~mm}$ or less) and complex composition of CPM make its emissions during the coal combustion process not to be ignored (Feng et al., 2018; Zhang et al., 2021).

At present, comparative research rarely focuses on the emission characteristics of CPM from units with different operating loads and flue gas temperature, and existing studies hardly consider the influence of the changes of coal-fired unit conditions when analyzing the emissions of CPM. Almost all these researches (Corio and Sherwell, 2000; Pei, 2015; Li et al., 2017a, b; Qi et al., 2017; Zheng et al., 2018a, b; Li et al., 2019; Song et al., 2020) were carried out in the power and industrial field, where operating loads and APCDs for coal-fired units remained stable. For sustainable development, China strongly supports the development of new energy power generation projects. Nevertheless, due to the problem of unstable power generation caused by the unstable sunshine time of new energy power generation such as solar, the vigorous development of photovoltaic power generation has led to the failure of most coal-fired units to operate at stable load (ShangGuan et al., 2019). By field sampling in the actual coal-fired unit under different operating loads, the emission level of $\mathrm{PM}_{2.5}$ and the component distribution of CPM are obtained, which can provide a reference for the removal of CPM emitted from coal-fired units with different loads. In addition, some studies (Bayless et al., 2000; Li et al., 2017b; Li et al., 2019) show that the temperature of coal-fired flue gas at the inlet of low-low temperature electrostatic precipitator (LLT-ESP) has a certain influence on the distribution characteristics of CPM. Therefore, this paper studies the emission characteristics of PM, especially CPM of inorganic and organic components from the coal-fired power unit under different loads and different flue gas temperatures at the inlet of LLT-ESP. These valuable data and conclusions will contribute to assessing the effect of the changes of load and flue gas temperature on the emission of CPM from coal-fired units and provide data references for CPM control.

In response to these circumstances, this research conducted a field sampling of condensable and filterable PM emitted from an ultralow-emission coal-fired power plant. The emission concentrations of CPM (including inorganic and organic compounds) and FPM of different particle sizes from the unit with different loads were discussed. Besides, the typical inorganic elements, the representative organic pollutants in CPM were qualitatively and quantitatively analyzed. The main content of the paper is as follows: (1) study the CPM and FPM emission concentration levels of the coal-fired unit under different loads. (2) study the effect of the changes of flue gas temperature at the inlet of LLT-ESP and operating load on the composition characteristics of inorganic and organic components in CPM. (3) study the emission and distribution characteristic of $n$-alkanes and phthalates in CPM from coal-burning flue gas.

\section{EXPERIMENTAL SECTIONS}

\subsection{Facility and Sampling Sites}

This study selected the unit (installed capacity, $1000 \mathrm{MW}$ ) from a representative coal-fired power plant with ultralow-emission retrofit to make a thorough analysis of the emission characteristics of CPM and FPM, respectively. The overall flue gas purification process of the coal-fired units is shown in Fig. S1, including the sampling sites in this work. The APCDs of the units consisted of a selective catalytic reduction (SCR) denitration device, a low-low temperature electrostatic precipitator (LLT-ESP), and a wet flue gas desulfurization (WFGD) system for the removal of $\mathrm{NO}_{\mathrm{x}}$, 
Table 1. Proximate and ultimate analyses of the feeding coal.

\begin{tabular}{|c|c|c|c|c|c|}
\hline \multirow{2}{*}{ Operating load } & \multicolumn{4}{|c|}{ Proximate and ultimate analyses } & \multirow{2}{*}{$Q_{\text {net,v,ad }}\left(\mathrm{MJ} \mathrm{kg}^{-1}\right)$} \\
\hline & $\mathrm{M}_{\mathrm{t}}$ & $A_{a d}$ & $\mathrm{~V}_{\mathrm{ad}}$ & $\mathrm{S}_{\mathrm{ad}}$ & \\
\hline $1000 \mathrm{MW}$ & 16.70 & 11.77 & 26.56 & 0.33 & 21.93 \\
\hline $850 \mathrm{MW}$ & & & & & \\
\hline $650 \mathrm{MW}$ & 17.00 & 11.45 & 26.81 & 0.37 & 22.36 \\
\hline
\end{tabular}

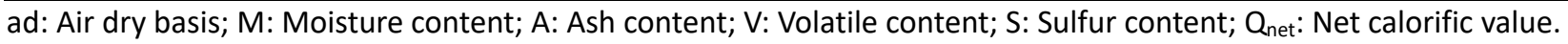

$\mathrm{PM}$, and $\mathrm{SO}_{2}$ in the flue gas produced by the combustion of pulverized coal in the boiler. Besides, a wet electrostatic precipitator (WESP) was posed in front of the chimney to remove fine particles and other pollutants.

Table 1 shows the results of proximate and ultimate analyses of the blended coal burned in the boiler. As seen from Table 1, the blended coal is low and medium ash coal with special low sulfur content and medium and high calorific value. Table S1 lists the distribution of sampling sites and the actual operating condition of the unit. During sampling, the load rate of the coal-fired unit dropped from $100 \%(1000 \mathrm{MW})$ to $85 \%(850 \mathrm{MW})$ and then to $65 \%$ (650 MW). Note that only when sampling at site $D$, the temperature of coal-fired flue gas at the inlet of LLT-ESP dropped from 100 to $90^{\circ} \mathrm{C}$. The APCDs of the unit was operated steadily during the sampling.

\subsection{Sampling Equipment and Methods}

Fig. S2 shows the schematic of the sampling system of CPM and FPM in the flue. The Dekati $\mathrm{PM}_{10}$ impactor was used to capture FPM and divide it into four categories according to the particle size $(\geq 10 \mu \mathrm{m}, 10-2.5 \mu \mathrm{m}, 2.5-1.0 \mu \mathrm{m}$, and $\leq 1.0 \mu \mathrm{m})$. CPM was attached to condenser, short and long stems impactor, and connector. A small amount of escaped CPM was captured by the membrane in the CPM filter. During the sampling, the flow rate was maintained at $10 \mathrm{~L} \mathrm{~min}^{-1}$. To avoid the interference of the moisture on the test results, the flue gas temperature before the $\mathrm{CPM}$ condenser requires to be controlled at $130^{\circ} \mathrm{C}$. More detailed descriptions of the functions of the sampling system and operating mode have been presented in the previous study (Li et al., 2017b; Li et al., 2019; Wu et al., 2021b).

\subsection{Analytical Procedure for Samples}

\subsubsection{Analytical procedure for filterable PM}

FPM was adsorbed by the filter membrane on the collector plate when the flue gas passed through the Dekati $\mathrm{PM}_{10}$ impactor. An electronic balance with a precision of $0.01 \mathrm{mg}$ was used to weigh the mass of the filter membrane that adsorbed FPM with different particle sizes.

The formula for calculating the concentration of FPM is as follows:

$c_{s}=\frac{g^{\prime \prime}-g^{\prime}-\xi}{V_{n d}}$

where $\mathrm{g}^{\prime}$ ( $\mathrm{mg}$ ) is the quality of the membrane with FPM adsorbed, g' (mg) is the quality of the clean membrane, $\xi(\mathrm{mg})$ is the weight gain of the blank sample on the field, and $\mathrm{V}_{\mathrm{nd}}(\mathrm{NdL})$ is the volume of flue gas under standard conditions.

Noted that the TPM (including FPM and CPM) concentration should be converted to the standard concentration under the condition of $6 \%$ oxygen and a drying schedule according to $G B / T$ 161571996 and GB 13223-2011, China.

\subsubsection{Analytical procedure for condensable PM}

Combined with Fig. S3, more specific pre-treatment procedures in detail have been made in previous studies (Li et al., 2017b; Li et al., 2019). A gas chromatograph/mass spectrometer (GC/MS) system (Agilent 7890B-5977A) was used for qualitative and semi-quantitative organic components in CPM. An ion chromatograph (model, Dionex ICS-2000) was used to quantify the anions $\left(\mathrm{F}^{-}, \mathrm{Cl}^{-}\right.$, $\mathrm{SO}_{4}{ }^{2-}, \mathrm{NO}_{3}{ }^{-}$) and $\mathrm{NH}_{4}{ }^{+}$. Inductively coupled plasma mass spectrometry (ICP-MS, AAS, model 
Thermo iCAP6300, quadrupole mass spectrometer) was used to quantitatively measure the metal elements ( $\mathrm{Na}, \mathrm{Mg}, \mathrm{Ca}, \mathrm{Al})$.

\subsubsection{Quantitative analysis of $n$-alkanes and phthalates in CPM}

The quantitative analysis of the two organic components in CPM was conducted using the standard external method. Eight concentration levels $\left(0.1,0.2,0.4,1.0,2.0,5.0,10.0\right.$ and $\left.20 \mathrm{mg} \mathrm{mL}^{-1}\right)$ of $n$-alkanes and phthalates standard solutions were selected. The standard curves of $n$-alkanes and phthalates were established for quantitative analysis based on the peak area and concentration. The operating parameters of the GC/MS are consistent for the detection of these two typical organic pollutants in CPM, which are shown in previous studies (Song et al., 2020; Wu et al., 2021d, c).

\subsubsection{Quality assurance and control}

Three consecutive samplings were conducted at each sampling site, and the average value was adopted as a result. Three groups of blank tests were conducted on the field to avoid accidental factors and reduce errors. The minimum detection limit of the GC/MS system reached $0.288 \mathrm{mg} \mathrm{Nm}^{-3}$ and $0.800 \mathrm{mg} \mathrm{Nm}^{-3}$ for organic and inorganic components in CPM. The correlation coefficients of the $\mathrm{n}$-alkanes and phthalates standard curves were all greater than 0.99 , which met the quantitative requirements of the experiment. The recovery rate of $n$-alkanes (the average is $87.17 \%$ ) and phthalates (the average is $90.40 \%$ ) was between $80 \%$ and $120 \%$, which demonstrated the high dependability of the experiment method. The specific measures have been described in previous studies (Li et al., 2017b; Wu et al., 2021d) and will not be repeated.

\section{RESULTS AND DISCUSSION}

\subsection{Emission Characteristics of FPM and CPM from the Unit}

The emission concentrations of FPM and CPM in coal-fired flue gas from the power unit with different loads and different flue gas temperatures are shown in Table 2. It is observed that the emission concentrations of FPM with different particle sizes from different loads of the unit are close, all below $3 \mathrm{mg} \mathrm{Nm}{ }^{-3}$. Previous studies (Li et al., 2017b; Li et al., 2019; Song et al., 2020) have shown that the removal efficiency of LLT-ESP could reach more than 99\% for FPM of various particle sizes, and WFGD and WESP also have certain removal effects for FPM. Results demonstrated that because the APCDs in the coal-fired power plant with ultra-low emission transformation have extremely high efficiency in the removal of FPM, factors such as flue gas temperature and unit load have little effect on the emission concentration of FPM. However, the $\mathrm{CPM}_{\mathrm{o}}$ (organic components in CPM) have obvious changes. It is worth noting that the concentration of $\mathrm{CPM}_{\mathrm{o}}$ in flue gas emitted from units increased with the decrease of the load. The CPM $\mathrm{C}$ is mainly the incomplete combustion products of the organic matter in fuel and the complex reactions such as resynthesis between small carbon molecules after combustion. Under the high-load operation of the unit, the thermal efficiency of fuel combustion is higher, and the fuel combustion is more uniform and sufficient, due to the optimal condition of boiler design is the full-load condition. According to the concentration of $\mathrm{CPM}_{\mathrm{O}}$ in flue gas at different temperatures (stages 3 and 4), it is found that the decrease in flue gas temperature leads to a significant decrease in the concentration of $\mathrm{CPM}_{0}$. This conclusion suggests that in the process of removing CPM from LLT-ESP, the main way of removal may be the change of phase state of CPM which is adsorbed on FPM and collected by dust collector plate due to the decrease of temperature. Nevertheless, there is little difference in the emission concentration

Table 2. Emission concentrations of FPM and CPM from the unit ( $\left.\mathrm{mg} \mathrm{Nm}^{-3}\right)$.

\begin{tabular}{|c|c|c|c|c|c|c|c|}
\hline \multirow{2}{*}{ Stage } & \multicolumn{3}{|c|}{ Condensable particulate matter } & \multicolumn{3}{|c|}{ Filterable particulate matter } & \multirow{2}{*}{$\begin{array}{l}\text { Total } \\
\text { particulate matter }\end{array}$} \\
\hline & Organic components & Inorganic components & Total & $\mathrm{FPM}_{2.5}$ & $\mathrm{FPM}_{10}$ & Total & \\
\hline 1 & 4.44 & 2.22 & 6.66 & 1.40 & 1.94 & 2.04 & 8.70 \\
\hline 2 & 5.51 & 1.45 & 6.69 & 0.83 & 1.09 & 1.20 & 8.16 \\
\hline 3 & 6.68 & 2.25 & 8.93 & 1.14 & 1.43 & 1.52 & 10.45 \\
\hline 4 & 4.05 & 2.61 & 6.66 & 1.77 & 2.64 & 2.75 & 9.41 \\
\hline
\end{tabular}




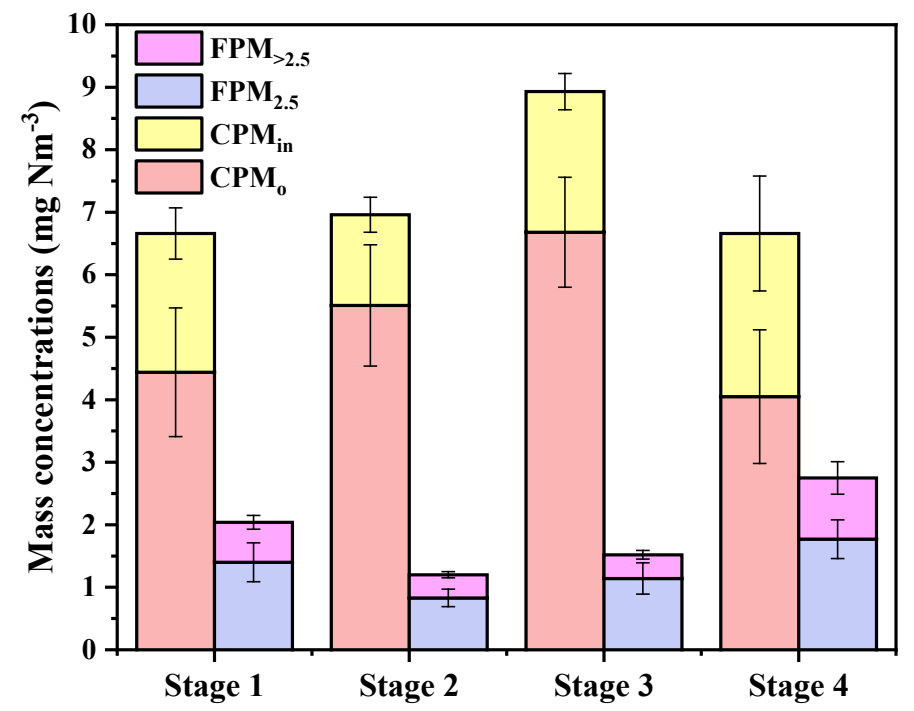

Fig. 1. Distribution of $F P M_{>2.5}, F P M_{2.5}, C P M_{i n}$, and $C P M_{0}$ under different stages.

of $\mathrm{CPM}_{\text {in }}$ (inorganic components in CPM) of coal-fired flue gas in the four stages, and the influence of load and temperature is limited. Note that the emission concentration of CPM is much higher than that of FPM, and it becomes the dominant component of TPM in the coal-fired flue gas.

Fig. 1 shows the concentration distribution of CPM with organic and inorganic components, and FPM with different particle sizes under different conditions. The concentrations of FPM emitted from coal combustion in the four stages all meet the requirements of the ultralow-emission standard $\left(\leq 5 \mathrm{mg} \mathrm{Nm}^{-3}\right.$ ) for particle emission concentration. It is noticeable that the proportion of $\mathrm{FPM}_{2.5}$ in the FPM emitted from coal-fired units reached $64.36-75.00 \%$. However, combined with the contribution of CPM, the emission concentration of $\mathrm{PM}_{2.5}$ of the coal-fired units reached 7.52-10.07 $\mathrm{mg} \mathrm{Nm}^{-3}$. Therefore, the PM $2.5 /$ TPM ratios reached $70.78-85.45 \%$. Fine particles, especially CPM, contributed the most. Moreover, the proportion of organic components in the CPM emitted from coal-fired units in the four stages exceeded $60 \%$, which is slightly higher than the data obtained in the laboratory (Peng et al., 2021). The difference from some studies (Damle et al., 1981; Corio and Sherwell, 2000; Pei, 2015) is that the fuel burned in this work is low sulfur coal, and the low $\mathrm{NO}_{x}$ combustion technique is applied in the power unit so that the concentration of sulfate and nitrate generated is reduced, making $\mathrm{CPM}_{\mathrm{o}}$ becomes the main fraction. It can also be seen from the figure that the CPMo/CPM ratios in the first (66.67\%) and fourth $(60.18 \%)$ stages are lower than those in the second $(79.17 \%)$ and third $(74.80 \%)$ stages, indicating that the higher the unit load and the lower the flue gas temperature at the inlet of LLT-ESP, the smaller the proportion of $C P M_{0}$. Therefore, it is of great significance to maintaining high load and low flue gas temperature operating conditions of coal-fired power units for reducing the emission of organic pollutants.

\subsection{Emission and Distribution Characteristics of Inorganic and Organic Components in CPM from the Unit}

\subsubsection{Emission and distribution characteristics of CPMin from the unit}

Fig. 2 and Table S2 show the emission concentrations of soluble ions in the inorganic components of CPM from the coal-fired unit with different loads. In this research, four metal cations ( $\mathrm{Na}^{+}$, $\mathrm{Ca}^{2+}, \mathrm{Mg}^{2+}$, and $\left.\mathrm{Al}^{3+}\right)$, four inorganic anions $\left(\mathrm{SO}_{4}{ }^{2-}, \mathrm{Cl}^{-}, \mathrm{F}^{-}\right.$, and $\left.\mathrm{NO}_{3}{ }^{-}\right)$, and $\mathrm{NH}_{4}{ }^{+}$in the inorganic components of CPM were quantitatively analyzed. The concentration distribution of inorganic ions in CPM in the flue gas emitted from the unit in the four stages was similar. Consistent with the previous research (Guo et al., 2006; Yang et al., 2014, 2018; Yuan et al., 2021) results, $\mathrm{SO}_{4}{ }^{2-}$ was still the most important soluble ion in the $\mathrm{CPM}_{\text {in }}$ from coal combustion, and its concentrations were $0.65-1.46 \mathrm{mg} \mathrm{Nm}^{-3}$. $\mathrm{Cl}^{-}$also accounted for a considerable proportion of $\mathrm{CPM}_{\text {in }}$ and its concentrations were close to $0.1 \mathrm{mg} \mathrm{Nm}^{-3}$. In contrast, $\mathrm{F}^{-}$and $\mathrm{NO}_{3}{ }^{-}$were almost non-existent in 

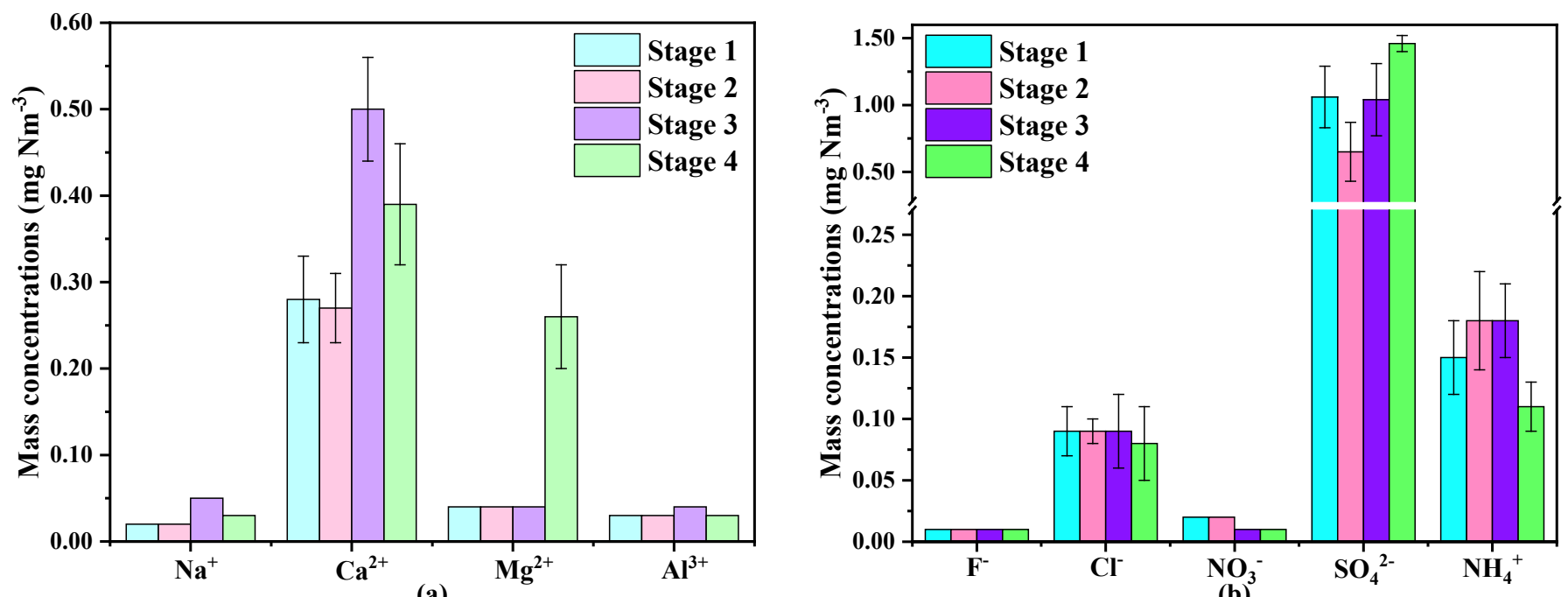

Fig. 2. The emission concentrations of (a) metal cations and (b) inorganic anions in CPM under different stages.

$\mathrm{CPM}_{\text {in }}$ from coal-fired flue gas. $\mathrm{Ca}^{2+}\left(0.27-0.50 \mathrm{mg} \mathrm{Nm}^{-3}\right)$ and $\mathrm{NH}_{4}^{+}\left(0.11-0.18 \mathrm{mg} \mathrm{Nm}^{-3}\right)$ were the higher concentrations of metal ion and cation in $\mathrm{CPM}_{\text {in }}$, respectively. Except for the concentration of $\mathrm{Mg}^{2+}$ in the fourth stage, the emission concentration of $\mathrm{Na}^{+}, \mathrm{Mg}^{2+}$, and $\mathrm{Al}^{3+}$ in the other stages was reduced to no more than $0.05 \mathrm{mg} \mathrm{Nm}^{-3}$.

Comparing the results of the first to third stages, the load of the coal-fired unit had no obvious effect on the concentration change of soluble ions in $\mathrm{CPM}_{\mathrm{in}}$. However, according to the results of the third and fourth stages, with the decrease of coal-fired flue gas temperature, the concentrations of $\mathrm{SO}_{4}{ }^{2-}$ and $\mathrm{Mg}^{2+}$ increased, while the concentrations of the other ions showed a downward trend. It is obvious that the influence of different loads of the unit and the change of flue gas temperature on the $\mathrm{CPM}_{\text {in }}$ emitted from the coal-fired boiler is mainly reflected in the concentration of $\mathrm{SO}_{4}{ }^{2-}$. Therefore, more field data are needed to verify the effect of flue gas temperature on inorganic components in CPM.

\subsubsection{Emission and distribution characteristics of $\mathrm{CPM}_{\mathrm{o}}$ from the unit}

Fig. 3 shows the distribution characteristics of organic compounds in CPM emitted from the coal-fired unit with different loads. Based on the study (Li et al., 2017b), the CPMo was divided into three categories via GC/MS analysis: hydrocarbons, esters, and other organic matters. Under different working conditions, the hydrocarbons in the organic components were the main components,

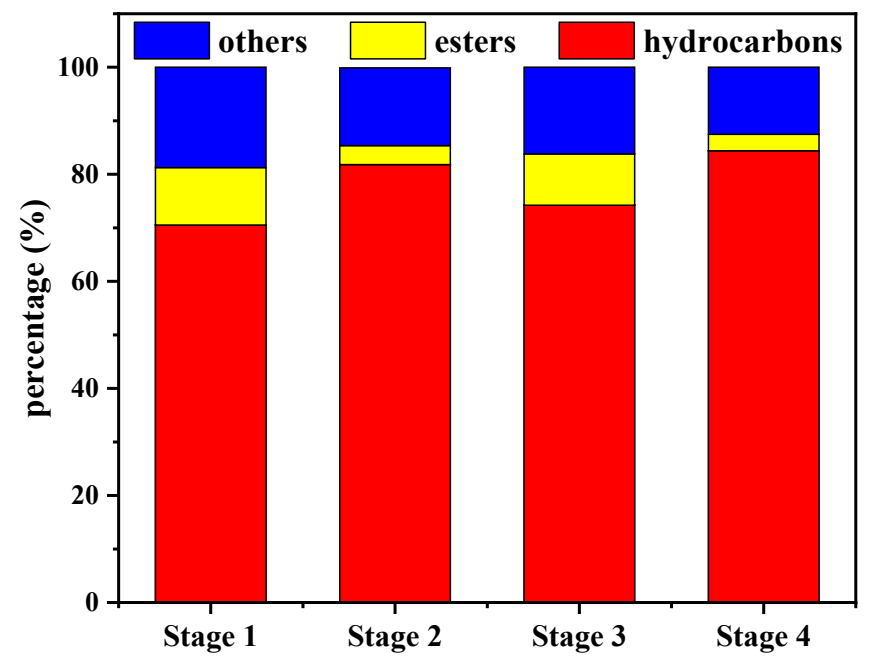

Fig. 3. Distribution proportion of organic components in CPM under different stages. 
accounting for $70.51-84.39 \%$. The proportion of esters was relatively small, ranging from 3.55$10.74 \%$, and the proportion of other organic compounds ranged from $12.52-18.75 \%$. According to the results of the third and fourth stages, with the decrease of coal-fired flue gas temperature, the proportion of hydrocarbons increased, while the proportions of esters and other organic matter decreased. However, the load of the unit had a limited effect on the percentage distribution of $\mathrm{CPM}_{\mathrm{o}}$ from coal combustion. There were dozens of alkanes in the analysis of hydrocarbons in CPM. Depending on the physical properties of this kind of organic matter, these alkanes were essentially liquid or solid at room temperature $\left(<30^{\circ} \mathrm{C}\right)$. Esters mainly included phthalates. Other organic matters were mainly halogenated organics and some sulfur- and nitrogen-containing organics.

\subsection{Emission and Distribution Characteristics of Two Typical Organic Pollutants in CPM from the Unit}

\subsubsection{Emission and distribution characteristics of n-alkanes in CPM from the unit}

Fig. 4(a) shows the emission concentrations of monocomponent C-N (n-alkanes in CPM) under a different load of the unit and different flue gas temperatures at the inlet of LLT-ESP. The total concentration of $\mathrm{C}-\mathrm{N}$ emitted from the units in the four stages was about $1 \mathrm{mg} \mathrm{Nm}^{-3}$, and the emission concentration increased with the decrease of boiler load and decreased with the decrease of flue gas temperature. The emission concentrations of $\mathrm{C}-\mathrm{N}$ under high load of the unit were 931.26 (stage $1,1000 \mathrm{MW}, 100^{\circ} \mathrm{C}$ ) and 969.49 (stage $2,850 \mathrm{MW}, 100^{\circ} \mathrm{C}$ ) $\mu \mathrm{g} \mathrm{Nm}^{-3}$, and the concentrations of C-N emitted from the unit under low load were 1353.50 (stage 3, $650 \mathrm{MW}$, $100^{\circ} \mathrm{C}$ ) and 1207.57 (stage $\left.4,650 \mathrm{MW}, 90^{\circ} \mathrm{C}\right) \mu \mathrm{g} \mathrm{Nm}{ }^{-3}$. The emission results illustrate that the operating load of the coal-fired unit has a greater impact on the emission concentrations of C-N than the changes of the flue gas temperature. One possible reason is that the $n$-alkanes in the flue gas of coal burning mainly came from the incomplete combustion of feeding coal, and the combustion efficiency of the boiler under high load was higher, so the $n$-alkanes were produced less. However, the changes in flue gas temperature only affected the degree of condensation of various substances in the coal-fired flue gas during the purification process. In addition, n-alkanes are highly volatile organic compounds, but the changes in flue gas temperature were relatively small, which had little effect on the actual emission of C-N.

Fig. 4(b) shows the distribution characteristics of monocomponent $\mathrm{C}-\mathrm{N}$ in the flue gas emitted from the unit in the four stages. It can be seen from the figure that the concentration distribution of $\mathrm{C}-\mathrm{N}$ in coal-fired flue gas at each stage was almost consistent, which increased with the increase of carbon number, and the main peak carbon was all $C_{31}$. It was found that the change in the load of the unit and flue gas temperature had no effect on the concentration distribution of
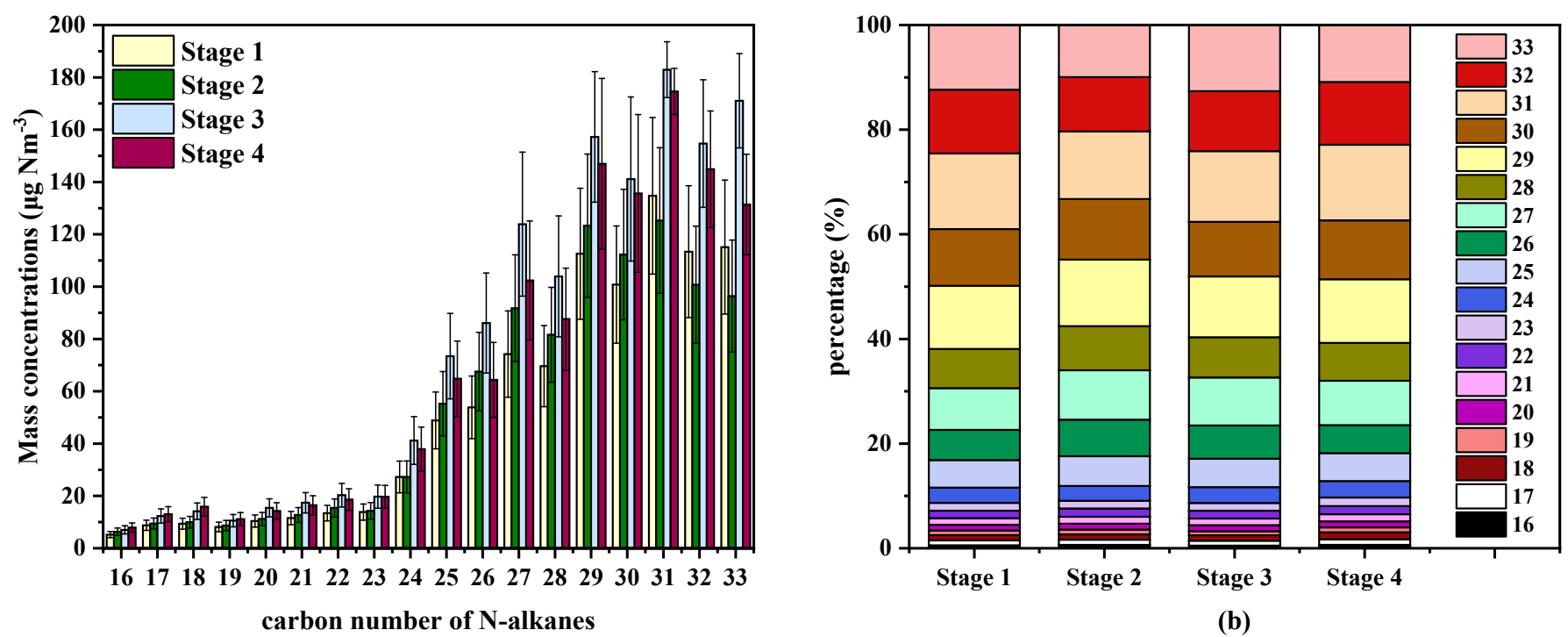

(b)

Fig. 4. (a) Emission concentrations of $n$-alkanes and (b) proportions of monocomponent $n$-alkanes in CPM under different stages. 


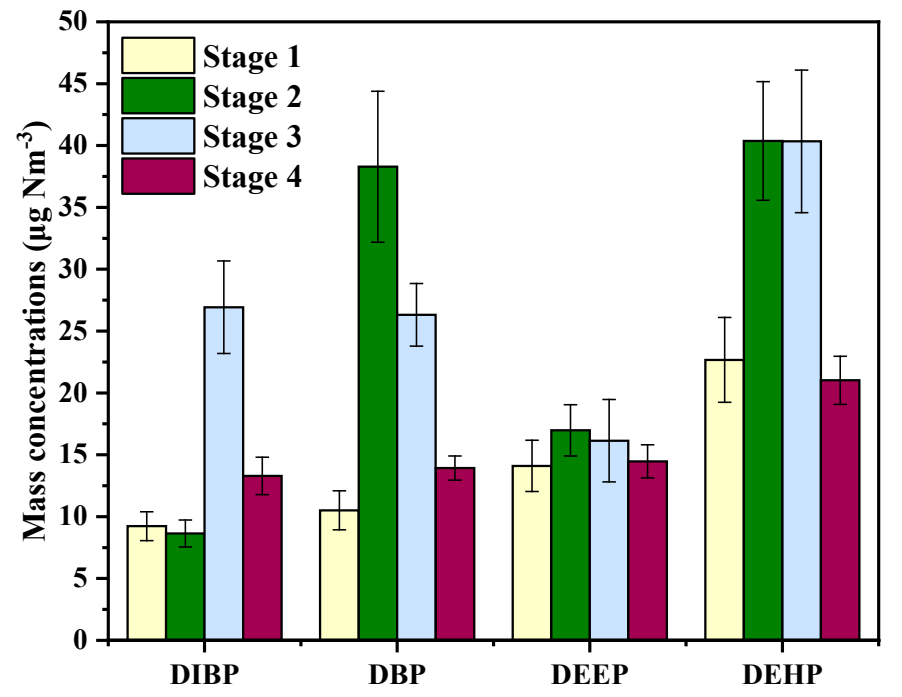

(a)

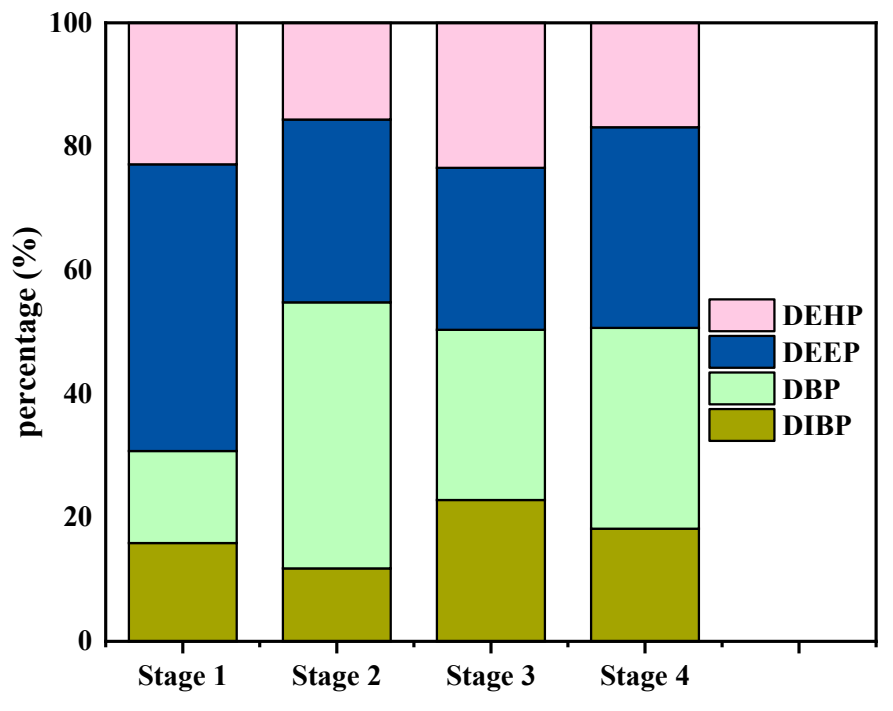

(b)

Fig. 5. (a) Emission concentrations of phthalates and (b) proportions of monocomponent phthalates in CPM under different stages.

monocomponent $\mathrm{C}-\mathrm{N}$ and the main peak carbon, but only affected the total concentration of C-N from coal combustion. Thus, maintaining the high load operation of coal-fired power units has a certain positive significance for reducing the emission of $\mathrm{C}-\mathrm{N}$.

\subsubsection{Emission and distribution characteristics of phthalates in CPM from the unit}

Fig. 5 shows the emission concentrations and proportions of monocomponent C-P (phthalates in CPM) under a different load of the unit and different flue gas temperatures at the inlet of LLT-ESP. The total emission concentration of C-P was the lowest in stage $1\left(1000 \mathrm{MW}, 100^{\circ} \mathrm{C}\right.$, $56.51 \mu \mathrm{g} \mathrm{Nm}^{-3}$ ) and the highest in stage $3\left(650 \mathrm{MW}, 100^{\circ} \mathrm{C}, 109.72 \mu \mathrm{g} \mathrm{Nm}^{-3}\right.$ ), which was the same as that of $\mathrm{C}-\mathrm{N}$. Nevertheless, the effect of flue gas temperature on the emission concentrations of C-P has increased. It is worth noting that compared to $\mathrm{C}-\mathrm{N}$, the emission concentration of C-P was relatively low. Besides, phthalates are semi-volatile organic pollutants, which may be more easily combined with FPM and removed by precipitators during the process of flue gas temperature reduction. Different load of the unit and flue gas temperature had a limited effect on the concentration of DEEP, while the effect on the other three monocomponent C-P (DIBP, DBP, and DEHP) was basically the same as the effect on C-N. The higher the load of the unit, the lower the coal-fired flue gas temperature, and the lower the concentrations of DIBP, DBP, and DEHP. DBP and DEEP always occupied a higher proportion in C-P, and contribute more to the concentration of C-P emitted from coal-fired units.

\subsubsection{Proportion of $n$-alkanes and phthalates in CPMo from the unit}

Fig. 6 shows the proportions of $n$-alkanes and phthalates in the organic components of CPM quantitatively detected under a different load of the unit and different flue gas temperatures at the inlet of LLT-ESP. The $n$-alkanes accounted for a large proportion of the organic components of CPM, reaching the range of $17.60-29.82 \%$. Although the proportion of phthalates in the organic components of CPM was slightly smaller (1.27-1.89\%), due to the huge amount of flue gas emitted by various coal-burning sources (including coal-fired power plants), the two types of organic matter contribute much to atmospheric pollutants.

\section{CONCLUSIONS}

Mass concentrations of PM (including FPM and CPM) emitted from a typical coal-fired power unit under different loads and different flue gas temperatures at the inlet of LLT-ESP were detected 


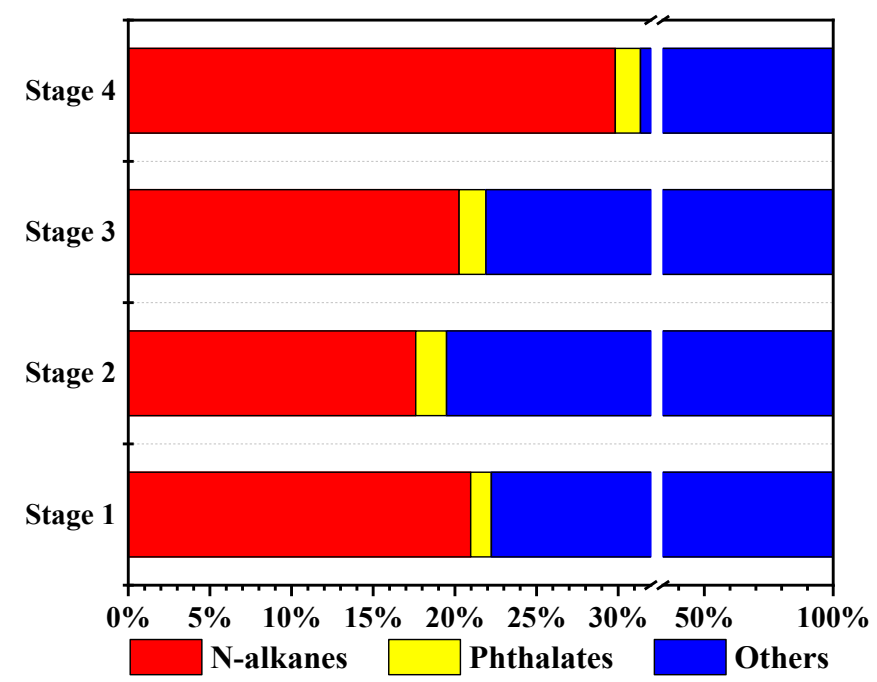

Fig. 6. The proportions of $n$-alkanes and phthalates in the organic components of CPM under different stages.

and analyzed. The influence of the changes of unit load and flue gas temperature on the emission characteristics of PM and the composition characteristics of CPM were explored. The analysis results are as follows: (1) The changes of unit load and flue gas temperature had a limited effect on the emission concentration of FPM; however, for CPM, the emission concentration was the lowest under high load and low flue gas temperature. Reducing flue gas temperature while maintaining the high load operation of coal-fired units has positive significance for reducing total PM emissions. (2) In the four stages, organic fractions were the main components of CPM emitted from the coalfired unit, and the proportions of hydrocarbons were more than $70 \%$. The $\mathrm{SO}_{4}{ }^{2-}$ was the inorganic component with the highest concentration in CPM, and the decrease of flue gas temperature led to the increase of its emission concentration. The load of the coal-fired unit did not affect the concentration change of soluble ions in CPM. (3) The effect of unit load and flue gas temperature changes on the total emission concentration of $n$-alkanes and phthalates in CPM was consistent with that on organic components in CPM, but the effect on monocomponent organics was not obvious. The concentrations of $n$-alkanes and phthalates in CPM accounted for more than $20 \%$ at all four stages. Due to the amount of flue gas produced by coal burning and the emission concentration of CPM is high, so its contribution to the organic pollutants in the atmosphere is considerable.

\section{ACKNOWLEDGMENTS}

The research was supported by the National key Research and Development program of China (2018YFB0605200).

\section{SUPPLEMENTARY MATERIAL}

Supplementary material for this article can be found in the online version at https://doi. org/10.4209/aaqr.210268

\section{REFERENCES}

Bayless, D.J., Jewmaidang, J., Tanneer, S., Birru, R. (2000). Kinetics of low-temperature homogeneous $\mathrm{SO}_{3}$ formation for use in flue gas conditioning for improved electrostatic precipitator performance. Proc. Combust. Inst. 28, 2499-2505. https://doi.org/10.1016/ S0082-0784(00)80665-7 
British Petroleum (BP) (2020). British Petroleum (BP) 2019 Statistical Review of World Energy 2019. British Petroleum (BP).

Cano, M., Vega, F., Navarrete, B., Plumed, A., Camino, J.A. (2017). Characterization of emissions of condensable particulate matter in clinker kilns using a dilution sampling system. Energy Fuels 31, 7831-7838. https://doi.org/10.1021/acs.energyfuels.7b00692

Corio, L.A., Sherwell, J. (2000). In-stack condensible particulate matter measurements and issues. J. Air Waste Manage. Assoc. 50, 207-218. https://doi.org/10.1080/10473289.2000.10464002

Damle, A.S., Ensor, D.S., Ranade, M.B. (1981). Coal combustion aerosol formation mechanisms: A review. Aerosol Sci. Technol. 1, 119-133. https://doi.org/10.1080/02786828208958582

Feng, Y., Li, Y., Cui, L. (2018). Critical review of condensable particulate matter. Fuel 224, 801-813. https://doi.org/10.1016/j.fuel.2018.03.118

Feng, Y., Li, Y., Zhang, X., Su, S., Zhang, Z., Gan, Z., Dong, Y. (2021). Comparative study on the characteristics of condensable particulate matter emitted from three kinds of coal. Environ. Pollut. 270, 116267. https://doi.org/10.1016/j.envpol.2020.116267

Guo, X., Hao, J., Duan, L., Yi, H., Li, X. (2006). Characteristics of water soluble ions emitted from large coal-fired power plant boilers. J. Tsinghua Univ. 046, 1991-1994.

Li, J., Li, X., Zhou, C., Li, M., Lu, S., Yan, J., Qi, Z., Shou, C. (2017a). Correlation between polycyclic aromatic hydrocarbon concentration and particulate matter during the removal process of a low-low temperature electrostatic precipitator. Energy Fuels 31, 7256-7262. https://doi.org/ 10.1021/acs.energyfuels.7b00145

Li, J., Qi, Z., Li, M., Wu, D., Zhou, C., Lu, S., Yan, J., Li, X. (2017b). Physical and chemical characteristics of condensable particulate matter from an ultralow-emission coal-fired power plant. Energy Fuels 31, 1778-1785. https://doi.org/10.1021/acs.energyfuels.6b02919

Li, X., Zhou, C., Li, J., Lu, S., Yan, J. (2019). Distribution and emission characteristics of filterable and condensable particulate matter before and after a low-low temperature electrostatic precipitator. Environ. Sci. Pollut. Res. 26, 12798-12806. https://doi.org/10.1007/s11356-019-04570-y

Lu, C.M., Dat, N.D., Lien, C.K., Chi, K.H., Chang, M.B. (2019). Characteristics of fine particulate matter and polycyclic aromatic hydrocarbons emitted from coal combustion processes. Energy Fuels 33, 10247-10254. https://doi.org/10.1021/acs.energyfuels.9b02201

Lu, S., Wu, Y., Chen, T., Song, J., Xu, Z., Tang, M., Ding, S. (2020). Influence of the combination system of wet flue gas desulfurization and a wet electrostatic precipitator on the distribution of polycyclic aromatic hydrocarbons in flue gas from a coal-fired industrial plant. Energy Fuels 34, 5707-5714. https://doi.org/10.1021/acs.energyfuels.0c00389

Morino, Y., Chatani, S., Tanabe, K., Fujitani, Y., Morikawa, T., Takahashi, K., Sato, K., Sugata, S. (2018). Contributions of condensable particulate matter to atmospheric organic aerosol over Japan. Environ. Sci. Technol. 52, 8456-8466. https://doi.org/10.1021/acs.est.8b01285

Pei, B. (2015). Determination and emission of condensable particulate matter from coal-fired power plants. Huanjing Kexue 36, 1544-1549. https://doi.org/10.13227/j.hjkx.2015.05.005

Peng, Y., Shi, N., Wang, T., Wang, J., Zhang, Y., Chen, W.Y., Sajjadi, B., Pan, W.P. (2021). Investigating the effect of flue gas temperature and excess air coefficient on the size distribution of condensable particulate matters. Fuel 298, 120866. https://doi.org/10.1016/j.fuel.2021.120866

Qi, Z., Li, J., Wu, D., Xie, W., Li, X., Liu, C. (2017). Particulate matter emission characteristics and removal efficiencies of a low-low temperature electrostatic precipitator. Energy Fuels 31, 17411746. https://doi.org/10.1021/acs.energyfuels.6b02692

Ruan, R., Liu, H., Tan, H., Yang, F., Li, Y., Duan, Y., Zhang, S., Lu, X. (2019). Effects of APCDs on PM emission: A case study of a $660 \mathrm{MW}$ coal-fired unit with ultralow pollutants emission. Appl. Therm. Eng. 155, 418-427. https://doi.org/10.1016/j.applthermaleng.2019.03.136

ShangGuan, X., Chang, H., Mei, H. (2019). Solar power generation technologies and their development trends and prospects. Energy Conserv. 60-63. https://doi.org/10.3969/j.issn. 2095-0802.2019.03.025

Song, J., Lu, S., Wu, Y., Zhou, C., Li, X., Li, J. (2020). Migration and distribution characteristics of organic and inorganic fractions in condensable particulate matter emitted from an ultralow emission coal-fired power plant. Chemosphere 243, 125346. https://doi.org/10.1016/j.chemo sphere.2019.125346

Sun, S., Liu, W., Guan, W., Zhu, S., Jia, J., Wu, X., Lei, R., Jia, T., He, Y. (2021). Effects of air pollution control devices on volatile organic compounds reduction in coal-fired power plants. Sci. Total 
Environ. 782, 146828. https://doi.org/https://doi.org/10.1016/j.scitotenv.2021.146828

Tong, D., Zhang, Q., Liu, F., Geng, G., Zheng, Y., Xue, T., Hong, C., Wu, R., Qin, Y., Zhao, H., Yan, L., $\mathrm{He}, \mathrm{K}$. (2018). Current emissions and future mitigation pathways of coal-fired power plants in China from 2010 to 2030. Environ. Sci. Technol. 52, 12905-12914. https://doi.org/10.1021/ acs.est.8b02919

Tsukada, M., Nishikawa, N., Horikawa, A., Wada, M., Liu, Y., Kamiya, H. (2008). Emission potential of condensable suspended particulate matter from flue gas of solid waste combustion. Powder Technol. 180, 140-144. https://doi.org/10.1016/j.powtec.2007.03.024

Wang, G., Ma, Z., Deng, J., Li, Z., Duan, L., Zhang, Q., Hao, J., Jiang, J. (2019). Characteristics of particulate matter from four coal-fired power plants with low-low temperature electrostatic precipitator in China. Sci. Total Environ. 662, 455-461. https://doi.org/10.1016/j.scitotenv. 2019.01.080

Wang, X., Jing, H., Dhungel, B., Wang, W.-N., Kumfer, B.M., Axelbaum, R.L., Biswas, P. (2016). Characterization of organic and black carbon aerosol formation during coal combustion: An experimental study in a $1 \mathrm{MW}$ pilot scale coal combustor. Fuel 180,653-658. https://doi.org/ 10.1016/j.fuel.2016.04.057

Wu, B., Bai, X., Liu, W., Lin, S., Liu, S., Luo, L., Guo, Z., Zhao, S., Lv, Y., Zhu, C., Hao, Y., Liu, Y., Hao, J., Duan, L., Tian, H. (2020). Non-negligible stack emissions of noncriteria air pollutants from coal-fired power plants in China: Condensable particulate matter and sulfur trioxide. Environ. Sci. Technol. 54, 6540-6550. https://doi.org/10.1021/acs.est.0c00297

Wu, X., Liu, W., Gao, H., Alfaro, D., Sun, S., Lei, R., Jia, T., Zheng, M. (2021a). Coordinated effects of air pollution control devices on $\mathrm{PAH}$ emissions in coal-fired power plants and industrial boilers. Sci. Total Environ. 756, 144063. https://doi.org/10.1016/j.scitotenv.2020.144063

Wu, Y., Xu, Z., Liu, S., Tang, M., Lu, S. (2021b). Emission characteristics of $\mathrm{PM}_{2.5}$ and components of condensable particulate matter from coal-fired industrial plants. Sci. Total Environ. 796, 148782. https://doi.org/10.1016/j.scitotenv.2021.148782

Wu, Y., Xu, Z., Liu, S., Tang, M., Lu, S. (2021c). Emission of organic components and distribution characteristics of PAHs in condensable particulate matter from coal-fired power and industrial plants. J. Energy Inst. 97, 109-116. https://doi.org/10.1016/j.joei.2021.04.011

Wu, Y., Xu, Z., Liu, S., Tang, M., Lu, S. (2021d). Migration and emission characteristics of n-alkanes and phthalates in condensable particulate matter from coal-fired sources. J. Cleaner Prod. 305, 127203. https://doi.org/10.1016/j.jclepro.2021.127203

Xu, X., Chen, C., Qi, H., He, R., You, C., Xiang, G. (2000). Development of coal combustion pollution control for $\mathrm{SO}_{2}$ and $\mathrm{NO}_{x}$ in China. Fuel Process. Technol. 62, 153-160. https://doi.org/ 10.1016/S0378-3820(99)00116-2

Yang, F., Li, Z., Liu, H., Feng, P., Tan, H., Zhang, S., Lu, X. (2021). Emission characteristics of condensable particulate matter and sulfur trioxide from coal-fired power plants. J. Energy Inst. 94, 146-156. https://doi.org/10.1016/j.joei.2020.12.003

Yang, H.H., Lee, K.T., Hsieh, Y.S., Luo, S.W., Li, M.S. (2014). Filterable and condensable fine particulate emissions from stationary sources. Aerosol Air Qual. Res. 14, 2010-2016. https://doi.org/10.4209/aaqr.2014.08.0178

Yang, H.H., Arafath, S.M., Lee, K.T., Hsieh, Y.S., Han, Y.T. (2018). Chemical characteristics of filterable and condensable $\mathrm{PM}_{2.5}$ emissions from industrial boilers with five different fuels. Fuel 232, 415-422. https://doi.org/10.1016/j.fuel.2018.05.080

You, C.F., Xu, X.C. (2010). Coal combustion and its pollution control in China. Energy 35, 44674472. https://doi.org/10.1016/j.energy.2009.04.019

Yuan, C., Wang, Z., Cheng, H., Liang, S., Hu, Y., Dong, X., Wu, J. (2021). Characteristics of watersoluble ions in condensable particulate matter emitted from stationary sources in Wuhan. Fuel 295, 120626. https://doi.org/10.1016/j.fuel.2021.120626

Zhang, F., Shang, X., Chen, H., Xie, G., Fu, Y., Wu, D., Sun, W., Liu, P., Zhang, C., Mu, Y., Zeng, L., Wan, M., Wang, Y., Xiao, H., Wang, G., Chen, J. (2020). Significant impact of coal combustion on VOCs emissions in winter in a North China rural site. Sci. Total Environ. 720, 137617. https://doi.org/10.1016/j.scitotenv.2020.137617

Zhang, J., You, C., Qi, H., Chen, C., Xu, X. (2006). Effect of solids concentration distribution on the flue gas desulfurization process. Environ. Sci. Technol. 40, 4010-4015. https://doi.org/10. 1021/es060665m 
Zhang, Z., Li, Y., Zhang, X., Zhang, H., Wang, L. (2021). Review of hazardous materials in condensable particulate matter. Fuel Processing Technol 220, 106892. https://doi.org/10. 1016/j.fuproc.2021.106892

Zheng, C., Hong, Y., Liu, S., Yang, Z., Chang, Q., Zhang, Y., Gao, X. (2018a). Removal and emission characteristics of condensable particulate matter in an ultralow emission power plant. Energy Fuels 32, 10586-10594. https://doi.org/10.1021/acs.energyfuels.8b02464

Zheng, C., Wang, L., Zhang, Y., Weng, W., Zhao, H., Zhou, J., Gao, X. (2018b). Co-benefit of hazardous trace elements capture in dust removal devices of ultra-low emission coal-fired power plants. J. Zhejiang Univ. 19, 68-79. https://doi.org/10.1631/jzus.A1700229

Zhou, Y., Zi, T., Lang, J., Huang, D., Wei, P., Chen, D., Cheng, S. (2020). Impact of rural residential coal combustion on air pollution in Shandong, China. Chemosphere 260, 127517. https://doi.org/10.1016/j.chemosphere.2020.127517 